\title{
Genetic risk: women's understanding of carrier risks in Duchenne muscular dystrophy
}

\author{
E P Parsons, A J Clarke
}

\begin{abstract}
This paper reports a study of 48 women (16 mothers and 32 daughters representing 28 families) who had lived with Duchenne muscular dystrophy (DMD) in their family. It looks at the way the women talked about their carrier risks during the course of an unstructured interview. It points to a significant difference between lay and health professionals' perspectives, in particular the thresholds they used to distinguish between high and low risk. A number of women, when quoting their risk in a mathematical form, confused their reproductive risks with their carrier risk, another indication of differential perceptions between the women and health professionals. There was evidence that several of the women did not retain their risk in a mathematical form but had translated it into a descriptive category which resolved their risk into greater certainty. (f Med Genet 1993;30:562-6)
\end{abstract}

Risk implies uncertainty. Formally speaking it is a concept of probability which is represented by a number between 0 (impossibility) and 1 (certainty). Concepts of risk are an integral part of clinical genetics and although tremendous advances have been made in molecular research, families are still making significant life decisions on the basis of estimations of risk rather than certainty.

Traditionally it was assumed that a strong positive correlation existed between risk and reproductive behaviour. In the terminology of Vlek' ${ }^{1}$ risk was seen as a 'stimulus' that elicited a largely predictable response. This approach, which underpinned the majority of early publications on genetic counselling, makes two assumptions: first, that clinical risk rates are precise and unambiguous and, second, that knowledge of these mathematical figures facilitates informed, rational decision making. It was widely accepted that the probability of having an affected child would have a predictable influence on reproductive behaviour and that the empirical risk figure would be subjectively interpreted in some relatively uniform way:

Institute of Medical Genetics, University of Wales College of Medicine, Heath Park, Cardiff CF4 4XN, UK E P Parsons A J Clarke

Correspondence to Dr Parsons.

Received 9 December 1992 Revised version accepted 29 March 1993.

". . . parents generally act in a way determined by whether they fall into high or low risk groups."'2 (p 129)

The same year Emery et $a l^{3}$ were disturbed to find that:

". . . a number of couples at high risk of having a child with a serious genetic disorder were undeterred from having further children. ..."'(p 726)

In recent years this more orthodox perspective has been challenged for being too simplistic, asocial, and failing to distinguish between risk in terms of an empirical rate and risk in terms of a subjective assessment. Formal probability, it is argued, is merely an empty mathematical concept waiting for subjective interpretation. ${ }^{14-6}$ Côté ${ }^{7}$ proposed that a clear distinction should be maintained in genetic counselling between the mathematical rate and the consequences of its outcome because the interpretation of genetic odds is essentially subjective and influenced by the perceived burden of the disease and other subjective considerations. This social interactionist, or social constructionist, perspective portrays risk as a multidimensional concept and is supported by a growing body of research which suggests that a number of factors other than risk influence reproductive patterning. ${ }^{8-12}$ It accepts that definitions of risk are constantly being negotiated and renegotiated between a person, their social situation, and the norms, values, and institutions of society. It recognises that no two people can ever experience the same situation in the same way because they each have very different previous biographies and different expectations. These influence how they define the situation, and different definitions lead to the construction of different patterns of behaviour. ${ }^{13-15}$ In the words of Thomas and Thomas ${ }^{16}$ :

"If men define situations as real they are real in their consequences." (p 572)

Understanding how people perceive and define their genetic carrier risk is important because of the vital role it plays in their subsequent social action. This should therefore be seen as significant in any assessment of how risk information is conveyed in genetic counselling.

This paper explores how a group of 48 women (16 mothers and 32 daughters, representing 28 families) talked about their potential carrier risks during the course of unstructured interviews. The ages of the mothers ranged from 46 to 68 years and the daughters from 19 to 49 years. The issues of the social classification of these women is discussed in detail elsewhere. ${ }^{10}$ Using the Registrar General's classification the social distribution was as follows

$\begin{array}{ll}\text { RG1 } & =1 \\ \text { RG2 } & =5 \\ \text { RG3 (N) } & =1 \\ \text { RG3 (M) } & =14 \\ \text { RG4 } & =2 \\ \text { RG5 } & =2 \\ \text { Economically inactive } & =23 \\ \text { Total: } & =48\end{array}$


The focused but unstructured interviews explored various aspects of the women's experience of living with DMD in the family. ${ }^{10}$ (The names of the women quoted are pseudonyms.) All 48 women had, at some point, been given a figure which represented their carrier risk. It was possible from their personal records to ascertain that figure and whether it had ever been altered. The purpose was not to test their memory or measure the effectiveness of genetic counselling, but to hear how they talked about their risk in the course of an informal conversation in their own home. Had they retained it in a mathematical form or translated it into a descriptive category? Was there any significance in the mathematical figures or the categories that they used to talk about their risk?

\section{The ordinal ranking of risk}

The acceptance that a carrier risk figure, despite any appearance of objectivity, includes a large component of subjective judgement means it is important to explore how both health professionals and women define the concept. Although there is little agreement on whether genetic counselling can ever be nondirective ${ }^{17}$ there is certainly a body of research which indicates that responses to information can be significantly influenced by the way it is presented. ${ }^{18-20}$ Clinicians and other health professionals involved in genetic counselling play an important role in presenting risk information. How do they interpret risk figures? How do they represent them in genetic counselling? Do they give them in a mathematical form or are they translated into various descriptive categories of probability? Lippman-Hand and Fraser $^{8}$ noted the tendency for counsellors to use semi-quantitative terms.

"At the same time they were relaying a numerical rate the counselors were qualifying it with descriptive statements of the same probability ("the chances of its happening again are remote - are very small')." (p 118)

Earlier Block et al ${ }^{21}$ found no overall consensus among medical professionals about how risk should be presented. It is this lack of consensus about how probability figures are translated into subjectively evaluated descriptive, or ordinal, categories which concerned O'Brien ${ }^{22}$ :

"The problem is that the same expression may convey different degrees of likelihood to different individuals." (p 89)

Shaw and Dear ${ }^{23}$ asked a group of mothers, medical students, and doctors to translate eight common probability expressions into a numerical value. They found a significant difference between lay and medical interpretations. They concluded that the use of verbal probability expressions by professionals should be restricted and that more information should be presented using numerical terms.

This lack of consensus in professional evaluations is well illustrated in genetic counselling publications where little agreement is evident about where thresholds should be numerically drawn between risks that are classified as 'high' and 'low'. Carter et $a l^{24}$ designated a recurrence rate of $10 \%$ as the divide, one author being prepared to say to parents with a risk below that figure ". . . in your place I would be prepared to take that risk". Emery et $a l^{3}$ also saw recurrence risks over $10 \%$ as 'high', but those between $5 \%$ and $10 \%$ as 'medium', and below $5 \%$ as 'low'. Later Emery et $a l^{25}$ reverted to a single distinction at $10 \%$. Wertz et al $^{26}$ found that genetic counsellors defined a recurrence risk above $25 \%$ as 'high' as did Reynolds et al. ${ }^{27}$ Hutton and Thompson ${ }^{28}$ also used $25 \%$ recurrence as the beginning of 'high' risk, but referred to risks between $5 \%$ and $25 \%$ as 'moderate' and below $5 \%$ as 'low'. More recently Norman et al, ${ }^{29}$ in their work on DMD, described carrier risks of $50 \%$ as 'high' (a recurrence risk in any pregnancy of $12.5 \%$ ), those between $5 \%$ and $50 \%$ as 'intermediate' (a recurrence risk of $1.25 \%$ to $12.5 \%$ ), and those below $5 \%$ as 'low' (a recurrence risk of $<1.25 \%$ ).

Any ordinal descriptive scale is, of necessity, arbitrary. The watershed between what is defined as 'high' and 'low' risk is subject to variable professional interpretation, but how did these definitions compare with those made by the women?

There were 36 women who talked about their carrier risks using a descriptive ranking, that is, they referred to them as either 'high' or 'low', 'bad', 'not so bad', or 'good'. It was possible to take this informal ordinal scale and see where they placed significant thresholds. There were two main watersheds: women ranked carrier risks below $5 \%$ as 'low' (a recurrence rate of DMD in any pregnancy of $1.25 \%$ ), and those above $20 \%$ (a recurrence rate of $5 \%$ ) as 'high'. Details of the way the women ranked their own risk on an ordinal scale are shown in the table.

What conclusions can be drawn from the numerical difference between professional and lay assessments of risk? It can be seen from the examples quoted that professionals use 'risk of recurrence' as their index and ranged in their assessment of 'low' risk as being less than $1.25 \%$ (a carrier risk in DMD of $5 \%$ ) to under $10 \%$ (a carrier risk in DMD of $40 \%$ ). In contrast the women were specifically talking about a figure they termed as their carrier risk and defined a risk below $5 \%$ as being 'low' (a recurrence risk of $1.25 \%$ ). 'High' risk for the professionals ranged from $12.5 \%$ to $25 \%$ (representing carrier risks in DMD of between $50 \%$ and $100 \%$ ). In contrast the women defined any risk above $20 \%$ of being a carrier as 'high' (a risk of recurrence of $5 \%$ ).

There are two potential explanations for this variation. Is it pure artefact? Were the indices used so poorly defined that the parties con-

Women's self-ranking of carrier risk.

\begin{tabular}{lccc}
\hline \multirow{2}{*}{$\begin{array}{l}\text { Carrier } \\
\text { risk }\end{array}$} & \multicolumn{2}{c}{ Women's self-ranking } & Total \\
\cline { 2 - 2 } & High & Low & \\
\hline$<5 \%$ & 0 & 8 & 8 \\
$5-9.9 \%$ & 1 & 1 & 2 \\
$10-19 \cdot 9 \%$ & 2 & 1 & 3 \\
$20-39 \cdot 9 \%$ & 2 & 0 & 2 \\
$>40 \%$ & 21 & 0 & 21 \\
Total number of women & 26 & 10 & 36 \\
\hline
\end{tabular}


cerned were unclear whether they were talking about carrier risks or risks of recurrence? Was it that the women felt a figure of $5 \%$ sounded 'low' and one of $20 \%$ sounded 'high'? If the same figures had been quoted as risks of recurrence would they have constructed the same thresholds? Was it that the professionals failed to distinguish between diseases and, like the women, designated figures that sounded appropriate for those classifications regardless of the inheritance pattern or its burden? The alternative explanation is that the women, as potential mothers of affected boys, were aware of the difference in the figures and were just more cautious in their assessments.

On the basis of this one study it is difficult to draw firm conclusions, but there is evidence that any translation of risk figures into emotive categories such as 'high' or 'low' needs to be treated with extreme caution. In addition, it is clear that the concurrent use of carrier and reproductive risks can give rise to confusion, if not to the professional, certainly to the lay persons concerned. It is this potential misunderstanding between the two rates that will be explored in the next section.

\section{Carrier risk and reproductive risks: professional and lay perspectives}

The concern, when the women talked about their risks in a mathematical form, was not its correctness per se but the significance of the figure they used and its representation. Twenty-eight of the 48 women talked about their risk using a mathematical form, either a percentage or a ratio. There were 13 who quoted it with a degree of accuracy (that is, within plus or minus $2 \%$ ), and with one exception these were all daughters. This could well reflect the greater relevance of this information to them and their more recent experience of genetic counselling. There were 15 women who were incorrect in their recall and it was evident that over half of them (8/15) had confused their carrier and reproductive risks. This difference is not only mathematically significant (a carrier risk rate is four times greater than a reproductive risk in any pregnancy), but it points to a potential difference between medical and lay perspectives.

In the laboratory, scientists are concerned with establishing indicators of carrier status and it is carrier information that is passed to the clinician. The general practice in genetic counselling is to begin with this carrier risk figure and then explain its implications in terms of reproduction.

The term 'carrier risk' has become part of the every day language of medical genetics but how meaningful and relevant is it to the people concerned? Lippman-Hand and Fraser ${ }^{9}$ found that many women were sceptical about the usefulness of rate information. There was evidence in this study that the majority of women did not feel that their personal identity had been spoiled and recognised the potential latency of their carrier status. ${ }^{1030}$ They pointed to significant critical junctures when the latent became manifest, for example, when they were establishing a relationship, when they were getting married or planning a family. The key issue for these women was not 'being a carrier' but its implications in reproduction. In the genetic counselling situation the women, faced with a range of figures, are likely to retain the one that has the most meaning for them: their risks in reproduction. All too easily this can subsequently become confused with their carrier risk.

During the interviews a number of the women recalled how the figures had been explained to them. One common theme in their accounts was the simplification of a percentage risk into odds.

"They gave me odds, I can't remember the actual odds, I was classed as high risk . . . they said I've got to have eight children to have one affected, I thought: Do I have to have eight children to prove them wrong?"

“. . . they said it's 100 to 1 , so I asked: If I have a hundred babies would it only happen to one of them?"

“. . . they used to say things like: Oh 1 in a 1000 , and you think: Oh well have I got to have a thousand babies before I have one that's like that?"

"At one time this doctor was telling me the chances I had, that was no good to me, I remember saying to them: What good is that to me, I would never want a load of children anyway, my mother had six."

There is clearly a need for further research into how complex genetic information and mathematical figures can be communicated, so that confusion and misunderstandings over levels of risk are kept to a minimum.

\section{Carrier risks: making sense of the figures}

In this study 25 women, even if they did make a mathematical reference to their risk in terms of either odds or a percentage, went on to talk in more general terms. It was evident from their conversations that they were trying to make some sense of the figures they had been given. Kessler ${ }^{31}$ noted that for information to be useful it needs to be transformed into 'personally meaningful units'. Mrs Hansford was doing just that when she was talking about her daughter's risks:

Mrs Hansford: "Camilla's rate is very high - 1 in 6; it was 1 in 3 , she is now 1 in 6 . Is that high or is there a lot higher?"

EPP: "Um. . . . ."

Pause. ....

Mrs Hansford: "Or is it about average?"

EPP: "It's difficult to say. ..."

Mrs Hansford: "Well about average I would think."

She was trying to locate Camilla's rate in terms of other rates, a process Lippman-Hand and Fraser" referred to as "calibrating odds against those faced by others". It was on this basis that Sally Abbott (CR 18\%) concluded her risk figure was 'not so high'. This definition was based on a comparison with her sister's figure of $42 \%$ rather than any medical or mathematical reasoning.

Carrier risk figures may give the appearance of being static and absolute but in reality they are constantly subject to refinement. They can be altered as a result of advances in molecular technology and because of changes in the 
family pedigree. Kitty Bain had her risk modified from $33 \%$ to $1 \%$ because of $\mathrm{CK}$ testing and the birth of two normal sons. What do women do with the revised figures? How do they build them into their understanding? Do they change their definitions? This issue is highly relevant in a period when there are rapid scientific advances. Mrs White (CR 5\%) and her daughter Pamela (CR 0.5\%) both believed that DMD in their family had been a 'one off' event. During the course of this study one of Mrs White's grandson's was found to be affected. This changed Mrs White to an obligate carrier and revised Pamela's risks to $7 \%$. In conversation with a doctor one day she asked what her new risk figure meant. The reply was:

"Well we consider $10 \%$ to be high so you must be moderately high ..."

Pamela was trying to translate formal probability analysis into something meaningful to her. The doctor was defining her carrier risks of $7 \%$ as 'moderate' and yet her sister, who had been given a risk of $0 \cdot 7 \%$, had given birth to an affected boy. Mathematical probability seemed meaningless in the light of her personal experience.

One strategy 11 of the women adopted, in the process of making their risks more meaningful, was to resolve them into something that was more certain. This is illustrated by the conversation with Mrs Poole (CR 90\%) and her daughter Victoria (CR 27\%).

Mrs Poole: "They do say that your risks have gone down a bit, what are they now? 1 in 7 or 1 in 8?"

Victoria: "Well I think's it's about 70 something, it's over 70."

Mrs Poole: "No she's definitely got it."

EPP: "What's that? She is a carrier?"

Mrs Poole: "Oh she is a carrier"

Victoria: "Oh I am a carrier."

Both mother and daughter were convinced that Victoria was a carrier and that this figure of $70 \%$ represented the chance of having an affected boy. They had translated a carrier risk into certain carrier status.

In contrast the Powell family (all with carrier risks below $2 \%$ ) had translated any risk into certain exemption. They were quite sure that none of them was a carrier.

"They took this blood test and there was nothing ... they said it was a one off or something ... . we did go down me and my daughter and another doctor said that there was no risk of her little boy."

"They said it was just a freak accident and it wouldn't affect us daughters. As I say it didn't really strike me that if it was a little boy it might have muscular dystrophy ... I think if it was hereditary it would have been a completely different thing, taken it more seriously. ..."

"I'm not a carrier ... If I had known I was a carrier I wouldn't have had children, no I wouldn't have taken a chance."

This tendency for women, particularly those with risks at the polarities, to resolve it into either certain carrier or non-carrier status was often accompanied by the use of descriptive 'one liners'. Jean Moffoot (CR $80 \%$ ) had been told by her mother that any boy she had would be affected and made no attempt to explore carrier risk or its significance. She had passed this message on to her husband before they got married:

"I just said to him: If we have children we can only have girls. I think the only thing he thought was that he couldn't have a son."

Other families also adopted the same strategy:

"I was given a percentage but I can't remember it . well it was more or less that I couldn't have a boy." (Daughter with a CR of $30 \%$ )

Mathematical percentages and ratios had been translated into meaningful everyday statements which became potential recipes for reproductive behaviour. This meant that these women were not constantly living with risk and uncertainty. The significance of this resolution into certainty and the interaction between these definitions and the women's reproductive patterning is discussed elsewhere. ${ }^{1012}$

\section{Conclusion}

This study, by its very nature, was small scale and it is therefore impossible to draw firm conclusions. However, its qualitative methodology meant that data were generated by the respondents themselves not by the researcher. This is significant for two reasons. First, it offers the potential framework for a more extensive quantitative investigation. Second, it highlights the difference between an objective risk rate and a subjectively defined risk experience. It points to the need for health professionals to build individual client definitions into genetic counselling because genetic risk and its implications cannot be understood outside a social context.

1 Vlek C. Risk assessment, risk perception and decision making about courses of action involving genetic risk: an overview of concepts and methods. In: Evers-Kiebooms $\mathrm{G}$, et al, eds. Genetic risk, risk perception and decision making. March of Dimes Birth Defects Foundation. New York: Alan R. Liss, 1987.

2 Pearn JH. Patients' subjective interpretations of risk offered in genetic counselling. $\mathcal{F}$ Med Genet 1973;10:129-34

3 Emery AEH, Watt MS, Clack ER. The effects of genetic counselling in Duchenne muscular dystrophy. Clin Genet counselling in Duc

4 Slovic P, Fischhoff B, Lichtenstein S. Perceived risk: psychological factors and social implications. Proc $R$ So chological factors and social im
Lond Section A 1981;376:17-34.

5 Douglas M, Wildavsky A. Risk and culture: an essay on the selection of technological and environmental dangers. Berkeley: University of California Press, 1982.

6 Murphy JW, Pilotta JJ. Research note. Identifying “a risk" persons in community based research. Sociol Health Illness 1987;9:62-75.

7 Côté GB. Odds in genetic counselling. 7 Med Genet 1982;19:455-7.

8 Lippman-Hand A, Fraser FC. Genetic counseling: provision and reception of information. $A m \mathcal{F}$ Med Genet 1979;3:113-27.

9 Lippman-Hand A, Fraser FC. Genetic counseling - the postcounseling period. 1. Parents' perceptions of uncerpostcounseling period. 1. Parents' percept
tainty. Am ₹ Med Genet 1979; 4:51-71.

10 Parsons EP. Living with Duchenne muscular dystrophy: women's understandings of disability and risk. PhD thesis, University of Wales, 1990.

11 Frets P, Duivenvoorden HJ, Verhage F, Niermeijer MF. Factors influencing the reproductive decision after genetic counselling. Am 7 Med Genet 1990;40:298-303.

12 Parsons EP, Atkinson PA. Genetic risk and reproduction. Sociol Rev (in press).

3 Schutz A. On phenomenology and social relations. Chicago: University of Chicago Press, 1970.

14 Schutz A, Luckmann B. The structure of the live world. London: Heineman, 1974

15 Thomas WI. Primitive behaviour: an introduction to the social sciences. New York: McGraw Hill, 1937.

16 Thomas WI, Thomas DS. The child in America. New York: Alfred A Knope, 1928.

17 Clarke AJ. Is non-directive genetic counselling possible? Lancet 1991;338:998-1001. 
18 Marteau T. Framing of information: its influence upon decisions of doctors and patients. Br $\mathcal{F}$ Soc Psychol 1989;28:89-94

19 Meadows J, Jenkinson S, Catalan J, Gazzard B. Voluntary HIV testing in the antenatal clinic: differing uptake rates for individual counselling midwives AIDS Care 1990;2:229-33.

20 Watson E, Mayall E, Chapple J, et al. Screening for carriers of cystic fibrosis through health care services. $B M \mathcal{F}$ 1991;303:505-7.

21 Block EV, DiSalvo M, Hall BD, Epstein CJ. Alternative ways of presenting empiric risk. In: Epstein CJ, et al, eds. Risk communication and decision making in genetic counse ing. Part c. Annual Review Of Birth Defects. New York: Alan Liss, 1978.

22 O'Brien B. Words or numbers? The evaluation of probability expressions in general practice. $\mathcal{F} R$ Coll Gen Pract 1989;39:98-100.

23 Shaw NJ, Dear PRF. How do parents interpret qualitative expressions of probability? Arch Dis Child 1990;656:520
24 Carter CO, Roberts JAF, Evans KA, Buck AR. Genetic clinic: a follow-up. Lancet $1971 ; \mathbf{i}: 281-5$.

25 Emery AEH, Raeburn JA, Skinner R, Holloway S, Lewis P. Prospective study of genetic counselling. $B M \mathcal{F}$ 1979;i:1253-6.

26 Wertz D, Sorenson J, Heeren T. Genetic counseling and reproductive uncertainty. Am f Hum Genet 1986;39:25364.

27 Reynolds BD, Puck MH, Robinson A. Genetic counseling: an appraisal. Clin Genet 1974;5:177-87.

28 Hutton EM, Thompson MW. Carrier detection and genetic counselling in Duchenne muscular dystrophy: a strophy: a follown Med Assoc f 1976;115:749-52.

29 Norman AM, Rogers C, Sibert JR, Harper PS. Duchenne muscular dystrophy in Wales: a 15 year study, 1971 to 1986. F Med Genet 1989;26:560-4.

30 Parsons EP, Atkinson PA. Lay construction of genetic risk. Sociol Health Illness 1992;14:437-55.

31 Kessler S. Psychological aspects of genetic counseling. VI A critical review of the literature dealing with education and reproduction. Am $\mathcal{F}$ Med Genet 1989;34:340-53. 